\title{
Hodgkin Lenfomalı Hastalarımızın Klinik ve Laboratuvar Özelliklerinin Değerlendirilmesi: Tek Merkez Deneyimi
}

\author{
Evaluation of Clinical and Laboratory Characteristics of Our Patients with Hodgkin Lymphoma: A Single Center
}

Experience

\author{
${ }^{1}$ Sevil Nalbant Avcı, ${ }^{2}$ Hava Üsküdar Teke, ${ }^{2}$ Neslihan Andıç, ${ }^{2}$ Nur Oguz Davutoğlu, \\ (11) \\ (10) \\ (117) \\ (ii) \\ ${ }^{2}$ Eren Gündüz, ${ }^{3}$ Ertuğrul Çolak
}

${ }^{1}$ Eskişehir Osmangazi Üniversitesi, İc Hastalıkları Anabilim Dalı, Eskișehir Türkiye

${ }^{2}$ Eskișehir Osmangazi Üniversitesi, Hematoloji Bilim Dalı, Eskişehir, Türkiye ${ }^{3}$ Eskișehir Osmangazi Üniversitesi, Biyoistatistik Bilim Dalı, Eskişehir, Türkiye
Correspondence: Sevil NALBANT AVCI Eskișehir Osmangazi Üniversitesi, İç Hastalıkları Anabilim Dalı, Eskișehir, Türkiye

e-mail: sevilnalbant@gmail.com

\section{Özet}

Çalışmamızda kliniğimizde Ocak 2008-Aralık 2018 tarihleri arasında, Hodgkin lenfoma (HL) tanısı alan hastaların; demografik, histopatolojik, prognostik özelliklerini belirlemeyi ve bu belirteçlerin sağkalım üzerindeki ilişkisini ortaya koymayı amaçladık. Çalışmamızda Eskişehir Osmangazi Üniversitesi Tıp Fakültesi Hematoloji Bilim Dalı’nda 2008-2018 yılları arasında, Dünya Sağlık Örgütü (WHO) 2008 sınıflamasına göre Hodgkin lenfoma tanısı almış olan 130 hastanın verileri retrospektif olarak değerlendirildi. Calıșmaya dahil edilen 130 hastanın \%61.5'i $(\mathrm{n}=80)$ erkek, yas ortalaması 46.5 \pm 15.8 (20-89) yıldı. Tanı sırasında hastaların \%37.7'si erken evre, \%62.3'ü ileri evreydi. En sık tanı evre II'de (\%34.6) konulmuştu. Hastalardan \%93.1'i klasik HL, \%6.9'u nodüler lenfosit predominant HL tanısı almıștı. Klasik HL tanılı hastaların \%49.6'si nodüler sklerozan HL (NSHL), \%15.7'si mikst selüler HL, \%7.4 lenfositten zengin HL, \%3.3’ü lenfositten fakir HL tanılıydı, \%24 ise klasik HL tanılı ancak alt tipi belirtilmemiști. NSHL tüm hastalarda, kadınlarda ve erkeklerde en sık görülen histolojik alt gruptu. Evrelere göre genel sağkalım (OS) ve relapssız sağkalımlara (RFS) bakıldığında evre I'de en yüksek, evre IV’te en düşüktü. Tüm hastalara göre bakıldığında 5 yıllık OS \%88.7, 5 yıllık RFS \%83.9, 10 yıllık OS \%82.2, 10 yıllık RFS \%82.4 olarak bulundu. Prognostik faktörlerin değerlendirilmesinde yaş ( $\mathrm{p}=0.001)$, ekstranodal tutulum ( $\mathrm{p}=0.007)$, kemik iliği tutulumu ( $\mathrm{p}=0.05)$, ECOG performans skoru ( $<<0.001)$, B semptom varllğ $1(\mathrm{p}=0.049)$ hemoglobin $(\mathrm{p}<0.0001)$, albümin $(\mathrm{p}<0.0001)$, alkalen fosfatazın (ALP) $(\mathrm{p}=0.0001)$ tek değişkenli analizde, mortalite üzerine anlamlı etkisi olduğu görüldü. Çok değişkenli analizde yaş $(\mathrm{p}<0.001)$, albümin $(\mathrm{p}=0.041)$, ALP ( $\mathrm{p}=0.005)$, lökosit sayısı ( $\mathrm{p}=0.028)$ prognostik faktörler olarak saptandı. Hastaların çoğu tanıda ileri evrede olup, 5 ve 10 yıllık genel ve relapssız sağkalımları evre arttıkça azalmaktadır. Yaș, ekstranodal tutulum, kemik iliği tutulumu, ECOG performansı, B semptom varlığı, anemi, hipoalbüminemi, ALP ve lökosit sayısı genel sağkalım üzerine etkili prognostik faktörlerdir.

Anahtar Kelimeler: Hodgkin lenfoma; prognostik faktörler; klinik özellikler

\section{Abstract}

In our study, patients diagnosed with Hodgkin lymphoma (HL) between January 2008 and December 2018 in our clinic; We aimed to determine demographic, histopathological and prognostic features and to reveal the relationship of these markers on survival. In our study, the data of 130 patients who were diagnosed with Hodgkin lymphoma in Eskişehir Osmangazi University Faculty of Medicine Hematology Department between 2008-2018 according to the World Health Organization (WHO) 2008 classification were analyzed retrospectively. $61.5 \%(n=80)$ of the 130 patients included in the study were male, the mean age was $46.5 \pm 15.8$ $(20-89)$ years. At the time of diagnosis, $37.7 \%$ of the patients were in the early stage and $62.3 \%$ were in the advanced stage. The most common diagnosis was made in stage (34.6\%). 93.1\% of the patients were diagnosed with classical HL and 6.9\% with nodular lymphocyte predominant HL. Of the patients with classic HL, $49.6 \%$ were diagnosed with nodular sclerosing HL (NSHL), 15.7\% with mixed cellular HL, 7.4\% with lymphocyte-rich HL, 3.3\% with lymphocyte-poor HL, $24 \%$ with classic HL but no subtype specified. NSHL was the most common histological subgroup in all patients, women, and men. Looking at overall survival (OS) and relapse-free survival (RFS) by stages, it was highest in stage I and lowest in stage IV. Considering all patients, 5-year OS was $88.7 \%$, 5-year RFS was $83.9 \%$, 10-year OS was $82.2 \%$, 10-year RFS was $82.4 \%$. In the evaluation of prognostic factors, age ( $\mathrm{p}=$ $0.001)$, extranodal involvement $(\mathrm{p}=0.007)$, bone marrow involvement $(\mathrm{p}=0.05)$, ECOG performance score $(\mathrm{p}<0.001)$, presence of B symptoms $(p=0.049)$, hemoglobin $(p<0.0001)$ ), albumin $(p<0.0001)$, alkaline phosphatase $(A L P)(p=0.0001)$ were found to have a significant effect on mortality in univariate analysis. In multivariate analysis, age ( $<<0.001)$, albumin $(\mathrm{p}=0.041), \mathrm{ALP}(\mathrm{p}=$ $0.005)$, leukocyte count $(\mathrm{p}=0.028)$ were determined as prognostic factors. Most of the patients are at advanced stage at diagnosis, and their overall and relapse-free survival of 5 and 10 years decreases as the stage increases. Age, extranodal involvement, bone marrow involvement, ECOG performance, presence of B symptoms, anemia, hypoalbuminemia, ALP and leukocyte count are prognostic factors that affect overall survival.

Keywords: Hodgkin lymphoma; prognostic factors; clinical features

Received 04.05.2021 Accepted 02.07.2021 Online published 02.07.2021 


\section{Giriş}

Hodgkin lenfoma (HL), lenfoid dokulardan köken alan bir malignitedir ve Reed-Sternberg hücresi adı verilen diagnostik dev hücreler ile karakterizedir. Tüm kanser türleri içinde $\% 1$, lenfomalar içinde $\% 25$ 'li bir orana sahiptir. HL genç erişkin dönemi (20-35 yaş) ve 55 yaş sonrası sik görülür. Gelişmiş ülkelerde insidans1, gelişmemiş ülkerelere oranla daha sıktır. Çocukluk çağı HL ise erişkindekinin tersine gelişmemiş toplumlarda sıktır (1). HL etyolojisi henüz tam olarak aydınlanmamış olsa da; enfeksiyöz sebeplerin, immünitenin ve ailesel faktörlerin etyolojide rolü olduğu bilinmektedir (2). Enfeksiyöz ajanlardan Ebstein-Barr virüsün (EBV) rolü pek çok çalışma ile gösterilmiştir (3). Klasik HL'nın yaşa ve cinsiyete göre dağılımı, histolojik alt gruplarına göre değişir. Nodüler sklerozan HL (NSHL) genç erişkinlerde ve kadınlarda sık görülmekteyken, mikst selüler HL (MSHL) siklıkla erkeklerde ve ileri yaşta sik görülür (4). Evreleme Ann Arbor evrelemesi ve Cotswolds modifikasyonuna göre yapilır. Evre I - II erken evre, III-IV (A veya B; I II B bulky hastalıkla birlikte) ileri evre hastalığı kapsar. Erken evre hastalıkta prognostik skorlama için Europan Organization for Research and Treatment of Cancer (EORTC) ve German Hodgkin's Lymphoma Study Group (GHSG), ileri evre hastalikta International Prognostic Score (IPS) kriterleri kullanılır (5). Erken evre ve ileri evre hastalar için prognostik skorlama kriterleri Tablo 1 ve Tablo 2' de verilmiştir.

Tablo 1. Evre I-II HL için prognostik skorlama sistemi

\begin{tabular}{|c|c|c|c|c|}
\hline Risk Faktörleri & GSHG & EORTC & NCIC & $\mathrm{NCCN}$ \\
\hline Yaş & & $\geq 50$ & $\geq 40$ & \\
\hline Histolojik Tip & & & MCHL, LDHL & \\
\hline $\begin{array}{l}\text { ESR ve B } \\
\text { semptomları }\end{array}$ & $\begin{array}{ll}\mathrm{ESR}>50 & \mathrm{~B}(-) \\
\mathrm{ESR}>30 & \mathrm{~B}(+)\end{array}$ & $\begin{array}{ll}\mathrm{ESR}>50 & \mathrm{~B}(-) \\
\mathrm{ESR}>30 & \mathrm{~B}(+)\end{array}$ & $\begin{array}{c}\text { ESR }>50 \text { B (-) veya } \\
\text { herhangi bir ESR B } \\
(+)\end{array}$ & $\begin{array}{c}\text { ESR }>50 \text { B (-) veya } \\
\text { herhangi bir ESR B } \\
(+)\end{array}$ \\
\hline $\begin{array}{l}\text { Nodal Tutulum } \\
\text { Bölgeleri }\end{array}$ & $>3$ & $>4$ & $>4$ & $>3$ \\
\hline Mediastinal Kitle & $\mathrm{MMR}>.33$ & $\mathrm{MTR}>.35$ & $\begin{array}{c}\text { MMR }>.33 \text { veya }>10 \\
\mathrm{~cm}\end{array}$ & $\mathrm{MMR}>.33$ \\
\hline $\begin{array}{l}\text { Ekstranodal } \\
\text { Tutulum }\end{array}$ & Var & & & \\
\hline Bulky Kitle & & & & $>10 \mathrm{~cm}$ \\
\hline
\end{tabular}

MMR, (Mediastinal Kitle Oranı): Mediastinal kitlenin transvers çapının, transtorasik çapa oranı, MTR (Mediastinal Torasik Oran): Mediastinal kitlenin transvers çapının, T5-6 seviyesi transtorasik çapa oranı, NCIC: National Cancer Intitute, Canada, NCCN: National Comprehensive Cancer Network

Tablo 2. İleri evre HL hastalarında olumsuz prognostik belirteçler (IPS-7)

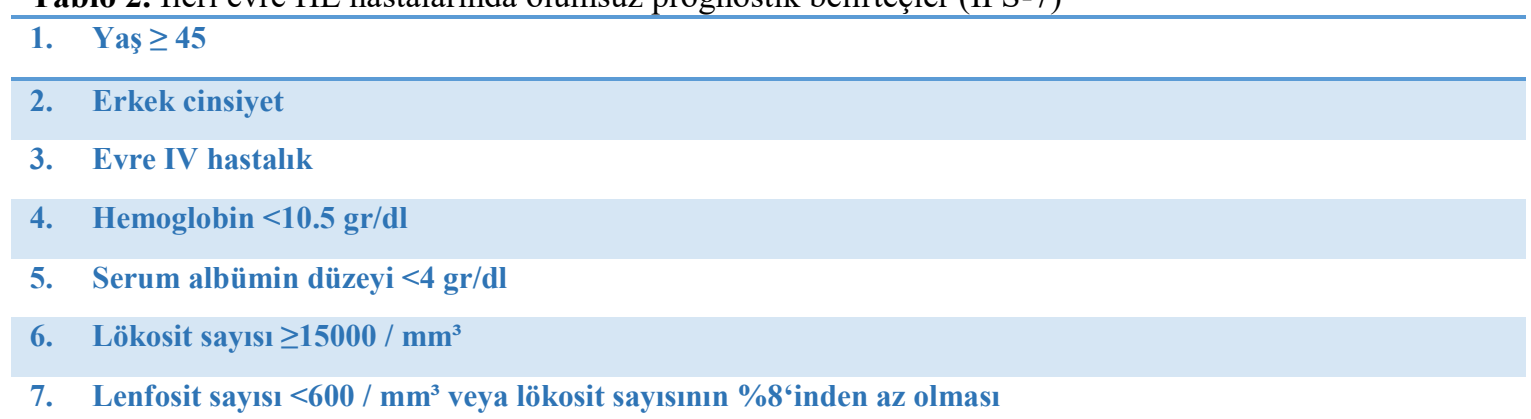


$\mathrm{Bu}$ çalışmada Eskişehir Osmangazi Üniversitesi İç Hastalıkları Anabilim Dalı Hematoloji Bilimdalı'nda 2008-2018 y1lları arasında HL tanısı almış ve WHO 2008 HL sınıflamasına göre sınıflandırılmış hastaların demografik, histopatolojik ve prognostik özelliklerini belirlemeyi ve bu belirteçlerin sağkalım üzerindeki ilişkisini ortaya koymayı amaçladik.

\section{Gereç ve Yöntemler}

Çalışmamızda Eskişehir Osmangazi Üniversitesi İç Hastalıkları Anabilim Dalı Hematoloji Bilim Dalı'nda 2008-2018 yılları arasında WHO 2008 sinıflamasina göre HL tanısı almış 130 hastanın verileri retrospektif olarak değerlendirilmiştir. Hastaların demografik ve klinik özellikleri, özgeçmiş, soygeçmiş, başvuru şikayetleri, B semptom varlığ , ECOG performans skoru, histopatolojik tipi, aldığ 1 tedaviler, relaps ve remisyon tarihleri, tanı an1 laboratuvar değerleri, hastanın son durumu (remisyonexitus-progrese hastal1k), exitus ise tarihi ve sebebi hasta dosyaları ve hastane bilgi kayit sisteminden temin edildi. Evreleme Ann Arbor Cotswold uyarlamasina göre yapıldı. Evre I - II erken, evre III-IV ileri evre olarak sınıflandırıldı. Prognoz tayini için erken evre hastalarda EORTC, ileri evre hastalarda IPS skorlaması kullanıldı. Genel sağkalım ve relapssız sağkalımın hesaplanabilmesi için tanı tarihi, relaps ve remisyon zamanları, hastaneye son başvuru tarihleri, yaşamını yitiren hasta varsa ölüm tarihleri hasta dosyalarından temin edildi. Tedavi tamamlandiktan en az 4 hafta sonra tam yanit elde edilmesi remisyon, tedavi tamamlandıktan sonra hastalığın aynı bölgeden ya da başka bölgeden tekrarlaması relaps, relapsin 3-12 ay aras1 meydana gelmesi erken relaps, 12 aydan sonra ortaya çıkması geç relaps, tedaviye yanıt alınamaması durumu refrakter hastalık olarak tanımland1. Hastanın ilk tanı tarihinden son başvuru tarihi ya da ölüm tarihine kadar olan süre genel sağkalım (OS), remisyon elde edilen tarihten relapsın ortaya çıkma tarihine kadar geçen süre relapssız sağkalım (RFS), remisyon elde edilen tarihten hastalı̆̆ın nüks etme tarihi ya da ölüm tarihi ya da son kontrol tarihine kadar geçen süre remisyon süresi olarak belirlendi.

Çalışma için Eskişehir Osmangazi Üniversitesi Girişimsel Olmayan Etik Kurul'undan 22.01.2019-28 numaralı onay1 alındi.

\section{İstatistiksel analiz}

Elde edilen veriler SPSS 21.0 sürümünde analiz edildi. Sağkalım analizleri KaplanMeier Yöntemi ile hesaplandı. İstatiksel değerlendirmede $\mathrm{p}<0.05$ anlamlı kabul edildi.

\section{Bulgular}

Çalışmaya dahil edilen 130 hastanın 50' si (\%38.5) kadın, 80'i (61.5) erkekti ve yaş ortalamas1 $46.5 \pm 15.8 \quad(20-89) \quad$ olarak hesaplandı. Tanı anında hastaların \%3.1 $(\mathrm{n}=4)$ evre I , \%34.6 $(n=45)$ evre II , \%30.8 $(n=40)$ evre III, \%31.5 $(n=41)$ evre IV idi. Hastaların \%37.7'si ( $\mathrm{n}=49)$ erken evre, \%62.3 $(\mathrm{n}=81)$ ileri evreydi. Hastalardan 121'i (\%93.1) klasik HL, 9'u (\%6.9) nodüler lenfosit predominant HL tanılıydı. Klasik HL tanılı hastalardan 60'1 (\%49.6) nodüler sklerozan, 19'u (\%15.7) mikst selüler, 9'u (\%7.4) lenfositten zengin, 4'ü (\%3.3) lenfositten fakir histolojik alt tipine sahipti. Hastalardan 29'unun (\%24) patoloji raporunda klasik HL tanısı belirtilmiş ancak alt tipi belirtilmemişti. Kadın hastaların $\% 45$ 'i $\quad(n=27)$, erkeklerin \%55'i $\quad(n=33)$ nodüler sklerozan alt tipine sahipti, kadın ve erkeklerde en s1k görülen histolojik alt tipin nodüler sklerozan olduğu görüldü. Nodüler sklerozan HL tanısı alan hastaların yaş dağ 11 เmı incelendiğinde 20'li ve 40'lı yaşlarda olmak üzere 2 pik değeri olduğu görüldü. Hastaların demografik özellikleri tablo halinde verilmiştir (Tablo 3). 
Tablo 3. Hastaların demografik ve klinik özellikleri

\begin{tabular}{|c|c|c|}
\hline & $\mathbf{n}$ & $\%$ \\
\hline Cinsiyet, Kadın/Erkek & $50 / 80$ & $38.5 / 61.5$ \\
\hline Yaş, yıl (ort \pm SS) & & \\
\hline \multicolumn{3}{|l|}{ Evre } \\
\hline Evre I & 4 & 3.1 \\
\hline Evre II & 45 & 34.6 \\
\hline Evre III & 40 & 30.8 \\
\hline Evre IV & 41 & 31.5 \\
\hline Erken evre & 28 & 21.6 \\
\hline İleri evre & 102 & 78.6 \\
\hline Ekstranodal hastalık & 57 & 43.8 \\
\hline Dalak tutulumu & 39 & 30 \\
\hline Karaciğer tutulumu & 15 & 11.5 \\
\hline Kemik iliği tutulumu & 23 & 17.7 \\
\hline B semptom varlığı & 88 & 67.7 \\
\hline Bulky hastalık/ Mediastinal bulky & $15 / 11$ & $11.5 / 8.5$ \\
\hline Multiple lenf nodu tutulumu & 128 & 98.5 \\
\hline \multicolumn{3}{|l|}{ Histolojik alt tip } \\
\hline NLPHL & 9 & 6.9 \\
\hline Klasik HL & 121 & 93.1 \\
\hline NSHL & 60 & 49.6 \\
\hline MSHL & 19 & 15.7 \\
\hline LFHL & 4 & 3.3 \\
\hline LZHL & 9 & 7.4 \\
\hline Alt tipi yok & 29 & 24 \\
\hline \multicolumn{3}{|l|}{ ECOG performans skoru } \\
\hline $\mathbf{0}$ & 101 & 77.7 \\
\hline 1 & 17 & 13.1 \\
\hline 2 & 7 & 5.4 \\
\hline 3 & 4 & 3.1 \\
\hline 4 & 1 & 0.8 \\
\hline Sigara kullanımı & 37 & 29.4 \\
\hline \multicolumn{3}{|l|}{ Yerleşim yeri } \\
\hline Merkez & 95 & 73.1 \\
\hline Kirsal & 35 & 26.9 \\
\hline
\end{tabular}


Hastaların $\quad \% 67.7$ 'sinde $\quad(n=88) \quad B$ semptomlar1, \%43.8'inde ( $\mathrm{n}=57)$ ektranodal hastalık saptand1, \%30'unda $(\mathrm{n}=39)$ dalak tutulumu, \%11.5 $(\mathrm{n}=15)$ karaciğer tutulumu, \%17.7'sinde $(\mathrm{n}=23)$ kemik iliği tutulumu mevcuttu. Hastaların \%11.5'inde $(\mathrm{n}=15)$ bulky kitle saptand, bunlardan 11'i (\%73.3) mediastinal bulky kitleydi. Tüm hastalar için takip süresi ortalama $151 \pm 10$ ay olarak hesaplandi. Tanı anındaki laboratuvar değerleri içerisinden hemoglobin $(\mathrm{p}<0.0001)$, albümin $(\mathrm{p}<0.0001)$, alkalen fosfatazın (ALP) $(p=0.001)$ tek değişkenli sağkalım analizine göre genel sağkalım üzerine istatistiksel olarak anlamlı oldukları görüldü. Tüm hastalar değerlendirildiğinde genel sağkalım (OS) \%85.4, relapssız sağkalım (RFS) \%86.2 olarak bulundu. Hastalar evrelere göre değerlendirildiğinde OS ve RFS evre I 'de en yüksek (\%100), evre IV'te en düşük (OS $\% 73.2$, RFS \%75.6) olduğu görüldü. Evreler arasinda OS $(p=0.044)$ ve RFS $(p=0.004)$ açısından farkın anlamlı olduğu görüldü (Şekil 1 ve Şekil 2). Tüm hastalar için 5 yıllık ve 10 yıllık genel sağkalım ve relapssız sağkalım sonuçları tablo halinde verilmiştir
(Tablo 4). Ekstranodal tutulumu olan 57 hasta (evre I 'de 0 , evre II 'de 3, evre III'te 14, evre IV 'te 40) değerlendirildiğinde, ekstranodal tutulumun sıklığı hastalığın evresi arttıkça artmaktaydı ve ekstranodal tutulum tek değişkenli varyant analizine göre sağkalım üzerine olumsuz etkisi olan bir risk faktörü olduğu görüldü $(\mathrm{p}=0.007)$. Bunun yanı sıra yaş $(p=0.001)$, ECOG performans skoru $(p<0.001)$, kemik iliği tutulumu $(p=0.05), B$ semptom varlığ $1 \quad(p=0.049)$ ve ileri evre hastaların prognostik skorlamasinda kullanılan IPS skorunun yüksek olmasının da $(p<0.001)$ tek değişkenli sağkalım analizine göre genel sağkalım üzerine olumsuz etkileri olan birer risk faktörü oldukları görüldü. Çoklu değişkenli analiz sonuçlarına göre yaş $(\mathrm{p}<0.001)$, albümin düzeyi $(\mathrm{p}=0.041)$, ALP $(p=0.005)$, lökosit sayıs1 $(p=0.028)$ da istatiksel olarak anlamlı bulundu. Dalak tutulumu, bulky kitle varlığ histolojik alt tipi, RT alımı, lenfosit sayıs1, eritrosit sedimentasyon hızı, laktat dehidrogenaz düzeyi gibi değişkenlerin sağkalım üzerine anlamlı etkileri saptanmadı $(p>0.05)$.

Tablo 4. Hastaların evrelere göre toplam, 5 ve 10 yıllık sağkalım analizleri

\begin{tabular}{|c|c|c|c|c|c|c|}
\hline & OS $\%$ & RFS $\%$ & $\begin{array}{c}5 \text { yıllık OS } \\
\%\end{array}$ & $\begin{array}{c}10 \text { yıllık OS } \\
\%\end{array}$ & $\begin{array}{c}5 \text { yıllık RFS } \\
\%\end{array}$ & $\begin{array}{c}10 \text { yıllık RFS } \\
\%\end{array}$ \\
\hline Evre I & 100 & 100 & 100 & 100 & 100 & 100 \\
\hline Evre II & 95.6 & 95.6 & 97.8 & 92 & 95.1 & 95.1 \\
\hline Evre III & 85 & 85 & 90.8 & 85.2 & 81.6 & 81.6 \\
\hline $\begin{array}{l}\text { Tüm } \\
\text { hastalar }\end{array}$ & 85.4 & 86.2 & 88.7 & 82.2 & 83.9 & 82.4 \\
\hline
\end{tabular}

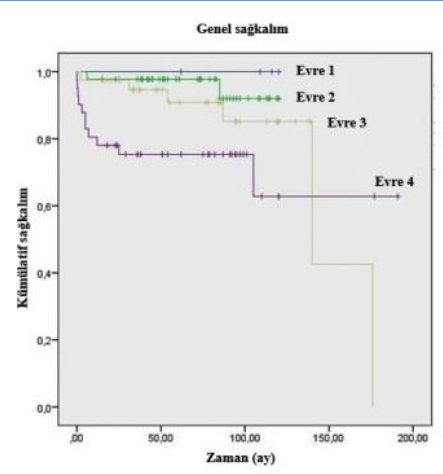

Şekil 1. Evrelere göre genel sağkalım eğrisi 


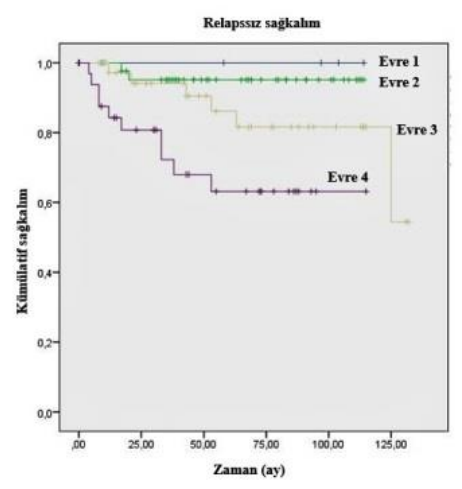

Şekil 2. Evrelere göre relapssız sağkalım eğrisi

\section{Tartışma}

Kliniğimizde takip edilen $130 \mathrm{HL}$ hastasını dahil ettiğimiz çalışmamızda hastaların epidemiyolojik, demografik ve prognostik özelliklerini belirlemeye çalıştık.

HL tüm kanser türleri içinde \%1, lenfomalar içinde \%25'lik bir orana sahiptir. 20'li ve $45^{\prime}$ li yaşlarda olmak üzere 2 pik yapar. Gelişmekte olan ülkelerde 20 yaşın altında görülme sıklığı fazlayken gelişmiş ülkelerde daha ileri yaşlarda ortaya çıkar (6). Gelişmiş ülkelerde genç erişkin dönemde en sik görülen HL alt tipi nodüler sklerozandır ve yüksek sosyoekonomik düzey ve küçük aile yapısı risk faktörü olarak ilişkilendirilmiştir. Gelişmekte olan ülkelerde ise en sik görülenler mikst selüler ve lenfositten fakir HL alt tipleridir, bu durum düşük sosyoekonomik düzey, kalabalık aile yapısı ve Ebstein-Barr virüs (EBV) maruziyetinin erken yaşta olması ile ilişkili bulunmuştur (7). Çalışmamızda hastalarımızın genel yaş ortalamas1 $46.5 \pm 15.8$ y1ld, NSHL tanıl1 hastaların 20'li ve 40'lı yaşlarda görülme sıklığının arttığı ve 2 pik değer yaptığı çalışmamızda da gözlendi.

Ülkemizde yapılan önceki yıllara ait çalışmalarda Üsküdar Teke ve arkadaşlarının çalışmasında erkek/kadın oranı 1.7 olarak bulunmuş ve en sik görülen alt tip MSHL olarak bulunmuştur (8). Altıntaş ve arkadaşlarının çalışmasında erkek/kadın oranı 2.1 ve en s1k görülen alt tip MSHL olduğu görülmüştür (9). Bizim çalışmamızda erkek/kadın oranı 1.6 olarak bulunmuş olup en s1k görülen alt tip NSHL oldu. Ülkemizde önceki yıllara ait çalışmalarda en sık MSHL görülürken çalışmamızın da dahil olduğu son yıllardaki yayınlarda en sik görülen alt tipin NSHL olduğu dikkati çekmiştir. Bu durumun toplumumuzdaki aile yapısının kalabalık aileden çekirdek aile yapısına evrilmesiyle ve sosyoekonomik düzeyin artması ile ilgili olabileceği düşünüldü.

Ülkemizde yapılan çalışmalara bakıldığında hastaların siklıkla tanı sirasinda evre II oldukları görülmüştür. Memiş ve arkadaşlarının çalışmasında en fazla hasta sayısı evre II 'de yer almaktaydı ve erken evre hasta sayıları, ileri evre hasta sayısından fazlaydı (6). Bizim çalışmamızda da en fazla hasta sayıs1 evre II 'deydi ancak toplam ileri evre hasta say1s1 $(n=81)$, erken evre hasta sayısından $(n=49)$ fazlaydı. Hastaların daha çok ileri evrede tanı alıyor olması hastaların başlangıç semptomlarının hastalar tarafından önemsenmemesi ve 1 . ve 2 . basamak sağlik kuruluşuna başvuran hastaların tanı koyma sürecindeki gecikme ile ilgili olabileceği düşünüldü.

HL hastalarında B semptomları tanı sirasında her 3 vakadan 1'inde görülür. En sık bulgu ateştir, genellikle geceleri yükselir ve düzensizdir. B semptomları prognozu belirlemede önemlidir ve kötü prognoz göstergesidir (10). Bizim çalışmamızda da B semptom görülme sıklığı \%67.7 olarak bulundu. B semptomlar içerisinde en sik ateş, ikinci olarak da terlemenin olduğu görüldü. B semptom oranının çalışmamızda yüksek 
bulunmuş olmasının ateş, kilo kaybı ve gece terlemesinin subjektif olmasindan kaynaklanabileceği düşünülmüştür.

HL sıklıkla lenf nodlarını tutar ancak tutulu lenf nodu ile ilişkili ya da ilişkisiz ekstralenfatik organ tutulumu da görülebilir. Ekstralenfatik organ tutulumu kötü prognozla ilişkilidir. En sık dalak, karaciğer, kemik iliğgi ve daha nadir olarak kemik, böbrek, akciğer tutulumları görülebilmektedir (11). Bizim çalışmamızda en sık dalak tutulumu olduğu görüldü (\%30), bunu kemik iliği (\%17.7) ve karaciğer (\%15) tutulumu takip etmekteydi. Ekstranodal tutulumun, hastalığın evresi arttıkça görülme sıklığının arttığını ve mortaliteyi artıran prognostik bir faktör olduğunu saptadık $(\mathrm{p}=0.007)$.

Günümüzde $\mathrm{HL}$ güncel tedavisinde tüm evrelerde 1. basamak kemoterapi rejimi 2-6 kür ABVD' dir. Radyoterapinin standart tedavide 1. basamaktaki yeri erken evre nonbulky hastalıkta interim PET'de Deauville 3, erken evre bulky hastal1kta interim PET'de Deauville 1-3 varlı̆̆ında ya da kemoterapi sonrası rezidü hastalık varlığındadır (12). Bizim çalışmamızda da hastaların \%99.2'si 1. basamak tedavide ABVD aldı. RT kayıtlarına ulaşılamadığından değerlendirilememiştir. HL hastalarında 2 kür ABVD sonras1 ara değerlendirme amaçlı çekilen PET sonucunun hastalığın prognozunu tayin etme açısından önemi büyüktür. 2 kür kemoterapi sonras1 çekilen PET bulgusu negatif olan hastalarda 2 yıllık progresyonsuz sağkalım $\% 90$ üzerindeyken, PET bulgusu pozitif olanlarda bu oranın \%10'un altında olduğu görülmüştür (13). Bizim çalışmamızda da 2 kür kemoterapi sonrası çekilen PET sonuçları $\% 80.3$ tam yanıt, \%16.4 k1smi yanıt, \%3.3 progrese hastalık şeklinde sonuçlanmıştır.

Çalışmamızda tüm hastalar değerlendirildiğinde 5 y1llık genel sağkalım (OS) \%88.7, relapssız sağkalım (RFS) \%83.9, 10 y1llı OS\%82.2, RFS \%82.4 olarak bulundu. Evrelere göre bakıldığında genel sağkalım $(p=0.044)$ ve relapssız sağkalım $(p=0.004)$ açısından evreler arasında anlamlı fark olduğu görüldü. 5 ve 10 yıllık sağkalımların da evre arttıkça azalmakta olduğu görüldü.

Erken evre HL risk değerlendirmesinde GSHG ve EORTC tarafindan önerilen prognostik faktörler kullanılırken, ileri evre hastaları değerlendirmek için ise IPS kriterleri kullanılmaktadır. Çalışmamızda ileri evre hastalarda IPS skorunun yüksek olmasının genel sağkalımı azalttığını gördük $(\mathrm{p}<0.001)$, bu skorlamada yer alan yaş, hemoglobin ve albümin düzeyinin de mortaliteyi artırdığını saptadik.

HL hastalarında erken ve ileri evre hastalar için çok sayıda prognostik faktör tanımlanmıştır. Yaş, eritrosit sedimentasyon hızı, B semptom varlığı, bulky kitle varlığ1, ekstralenfatik organ tutulumu, cinsiyet, evre, hemoglobin ve albümin düzeyleri bu faktörlerin en önemlileridir (14). HL üzerine prognostik faktörleri de araştırdığımız çalışmamızda tüm hastalar için yapılan tek değişkenli analizde yaş, B semptom varlığ 1 , ekstralenfatik organ tutulumu, ECOG performans skoru, kemik iliği tutulumu, anemi, hipoalbüminemi ve alkalen fosfataz düzeyi sağkalım üzerine etkili faktörler olarak bulundu. $\mathrm{Bu}$ prognostik belirteçler çok değişkenli analiz ile değerlendirildiğinde yaş, lökosit sayıs1, albümin ve alkalen fosfataz sağkalım üzerine anlamlı etkileri olan kötü prognostik faktörler olarak önemini korudular. Tek değişkenli analiz sonuçları genel olarak literatür ile uyumlu bulunurken, çok değişkenli analiz sonuçlarında yaş ve albümin değerinin literatür ile uyumlu olduğu görüldü.

Sonuç olarak; çalışmamızda en sık nodüler sklerozan tip Hodgkin lenfoma görülmüş olup, erkeklerde daha sik görülmektedir. Hastalar genelikle ileri evrede tan1 almaktadırlar. Genel sağkalım üzerine etkili faktörlerin yaş, ekstranodal tutulum, ECOG performans skoru, kemik iliği tutulumu, B semptom varlığı, hipoalbüminemi, anemi ve alkalen fosfataz düzeyi olduğu görüldü. 


\section{KAYNAKLAR}

1. Ansell SM, editor Hodgkin lymphoma: diagnosis and treatment. Mayo Clinic Proceedings; Elsevier. 2015

2. Kharazmi E, Fallah M, Pukkala E, Olsen JH, Tryggvadottir L, Sundquist K, et al. Risk of familial classical Hodgkin lymphoma by relationship, histology, age, and sex: a joint study from five Nordic countries. Blood. 2015;126:1990-5.

3. Hjalgrim H, Askling J, Rostgaard K, HamiltonDutoit S, Frisch M, Zhang JS, et al. Characteristics of Hodgkin's lymphoma after infectious mononucleosis. N Engl J Med. 2003;349:1324-32.

4. LaCasce AS, Ng AK. Hodgkin lymphoma: Epidemiology and risk factors.

5. Meignan M, Gallamini A, Meignan M, Gallamini A, Haioun C. Report on the first international workshop on interim-PET scan in lymphoma. Leukemia \& lymphoma. 2009;50:1257-60.

6. Memiş Y, Kandaz M, Serdar L, Aynaci Ö, Şahbaz A, Soydemir G, et al. Hodgkin lenfomal hastaların klinik özellikleri ve tedavi sonuçlarının geriye dönük analizi: Tek merkez deneyimi. Turkish Journal of Oncology/Türk Onkoloji Dergisi. 2015;30.

7. Oliveira DEd, Bacchi MM, Abreu ES, Niéro-Melo L, Bacchi CE. Hodgkin disease in adult and juvenile groups from two different geographic regions in Brazil: characterization of clinicopathologic aspects and relationship with Epstein-Barr virus infection. American Journal of Clinical Pathology. 2002:25-30.

8. TEKE HÜ. Hodgkin Lenfoma Tanıs1 Alan 103 Olgunun Retrospektif Olarak Değerlendirilmesi. Osmangazi Tip Dergisi. 2008;30:25-31.

9. Altintaş A, Çil T, Kaplan Ma, Atay Ae, Işikdoğan $\mathrm{A}$, Büyükbayram $\mathrm{H}$, et al. Hodgkin Lenfoma Olgular` $\mathrm{m}>\mathrm{z}$ : Klinik ve Patolojik Değ erlendirme.

10. Gallamini A, Hutchings M, Ramadan S, editors. Clinical presentation and staging of Hodgkin lymphoma. Seminars in hematology; Elsevier. 2016

11. Even-Sapir E, Lievshitz G, Perry C, Herishanu Y, Lerman $\mathrm{H}$, Metser U. Fluorine-18 fluorodeoxyglucose PET/CT patterns of extranodal involvement in patients with NonHodgkin lymphoma and Hodgkin's disease. Radiologic Clinics of North America. 2007;45:697-709.

12. Hoppe RT, Advani RH, Ai WZ, Ambinder RF, Armand P, Bello CM, et al. Hodgkin Lymphoma, Version 2.2020, NCCN Clinical Practice Guidelines in Oncology. Journal of the National Comprehensive Cancer Network J Natl Compr Canc Netw. 2020;18:755-81.

13. Hutchings M, Loft A, Hansen M, Pedersen LM, Buhl T, Jurlander J, et al. FDG-PET after two cycles of chemotherapy predicts treatment failure and progression-free survival in Hodgkin lymphoma. Blood. 2006;107:52-9.
14. Cuccaro A, Bartolomei F, Cupelli E, Galli E, Giachelia M, Hohaus S. Prognostic factors in hodgkin lymphoma. Mediterr J Hematol Infect Dis. 2014;6:e2014053. 